\title{
O AUXÍLIO MORADIA CONCEDIDO AOS MEMBROS DA MAGISTRATURA: UMA ABORDAGEM A PARTIR DO PRINCÍPIO DA IGUALDADE
}

\author{
Jesus Tupã Silveira Gomes* \\ Lucas Uelinton Graciolli** $^{* *}$
}

\begin{abstract}
Resumo:
Em 2014, o CNJ criou o auxílio-moradia em favor dos magistrados, o que supostamente contraria o princípio da igualdade previsto na Constituição Federal de 1988. O objetivo do presente estudo consiste em aferir, com fundamento no constitucionalismo garantista e no Direito da Antidiscriminação, se ele está em conformidade com o Direito pátrio. Assim, examinamos o princípio da igualdade, mapeamos as prerrogativas concedidas aos grupos vulneráveis e analisamos a conformidade do benefício com o ordenamento vigente. Realizamos pesquisa documental, com a revisão da bibliografia, utilizando o método hipotético-dedutivo. Os resultados indicam que o auxílio-moradia contraria o princípio da igualdade.
\end{abstract}

\section{Palavras-chave:}

Auxílio Moradia; Magistratura; Princípio da Igualdade; Discriminação; Desigualdade

\section{THE HOUSING AID GRANTED TO MEMBERS OF THE MAGISTRATURE: AN APPROACH FROM THE EQUALITY PRINCIPLE}

\begin{abstract}
:
In 2014, the CNJ created housing assistance in favor of magistrates, which allegedly contradicts the principle of equality provided for in the 1988 Federal Constitution. whether it complies with the law of the country. Thus, we examine the principle of equality, map the prerogatives granted to vulnerable groups and analyze the benefit's conformity with the current legislation. We conducted documentary research, with a review of the bibliography, using the hypotheticaldeductive method. The results indicate that housing assistance is contrary to the principle of equality.
\end{abstract}

\section{Keywords:}

Housing assistance; Judiciary; Principle of Equality; Discrimination; Inequality

\footnotetext{
*Doutorando em Direito e Sociedade pela Universidade La Salle - Unilasalle. Mestre em Direitos Humanos pelo Centro Universitário Ritter dos Reis - UniRitter. Especialista em Direito de Família e Sucessões pela Faculdade de Desenvolvimento do Rio Grande do Sul - FADERGS. Bacharel em Direito pela Universidade Federal do Rio Grande do Sul. Membro do Grupo de Pesquisa Garantismo e Constitucionalismo Popular. Servidor do Tribunal de Justiça do Estado do Rio Grande do Sul - TJRS. Email: jtsg1976@ gmail.com. Orcid: https://orcid.org/00000001-6741-5938.

${ }^{* *}$ Mestrando em Direito e Sociedade pela Universidade La Salle - UniLaSalle. Pós-graduando em Docência no Ensino Superior pelo Centro Universitário Ritter dos Reis - UniRitter. Bacharel em Direito pela Universidade La Salle - Unilasalle. Email: lucas_uelinton@ hotmail.com. Ordid: https://orcid.org/0000-0003-1259-8807.
} 


\section{INTRODUÇÃO}

A Constituição Federal da República Federativa do Brasil (CRFB) conferiu algumas prerrogativas aos membros da magistratura, visando a garantir sua independência frente aos Poderes Legislativo e Executivo. Em consequência, os magistrados gozam de uma posição privilegiada na sociedade, constituindo uma classe com rendimentos acima da média dos demais trabalhadores, o que contribui para o desequilíbrio social, tendo em vista o número elevado de vantagens conferidas aos juízes.

Tais prerrogativas tornam-se utensílios - potencialmente determinantes - capazes de colocar em risco alguns princípios que são pilares do Estado Democrático de Direito. Deste modo, os privilégios e atribuições conferidos aos magistrados são fundamentados e, positivados por meio uma retórica meritocrata e estruturada na relevância de sua posição.

Dessa forma, a atual posição social diferenciada conferida aos magistrados tem como resultado a construção de uma estrutura semelhante às inclinações dos juízes e os das aristocracias econômicas e políticas do país, configurando, nesses moldes, um distanciamento da realidade social do cidadão comum brasileiro. Diante das intempéries da sociedade brasileira, um fator que permanece em evidência é a importância da remoção ou redução das condições desiguais.

Sendo assim, é na esfera normativa que se ascende o suporte positivista responsável pela ampliação de privilégios e prerrogativas que são capazes de aumentar esse distanciamento entre as classes sociais brasileiras, visto que o benefício de auxílio moradia à magistratura. Portanto, buscou-se compreender os mecanismos que condicionam o aumento dessas desigualdades sociais e o porquê da discriminação de beneficiar uma classe em detrimento de outras.

Nesse contexto, o auxílio moradia conferido aos magistrados brasileiros constitui um privilégio que não é concedido ao trabalhador comum, devendo-se analisar se ele constitui uma prerrogativa legítima de uma classe já privilegiada.

O objetivo principal do estudo é examinar, a partir do constitucionalismo garantista, proposto por Luigi Ferrajoli, e do Direito da Antidiscriminação, defendido por Roger Raupp Rios, se a concessão do auxílio moradia aos magistrados encontra-se em conformidade com o ordenamento jurídico pátrio. Como objetivos específicos, pretendemos mapear os elementos 
que compõem o direito à igualdade prevista no artigo $5^{\circ}$, caput, da CRFB; averiguar os elementos constitucionais e legais que justificam o tratamento diferenciado a determinados indivíduos ou grupos sociais; e apontar, a partir do exame da estrutura social brasileira, as razões pelas quais a concessão do benefício mostra-se irregular; uma vez que não se destina a promover a igualdade material de um grupo vulnerável, mas sim a estabelecer uma prerrogativa exclusiva em favor de uma classe já privilegiada.

O presente estudo foi desenvolvido por meio de pesquisa documental, com o uso do método hipotético-dedutivo. Como forma de análise, utilizou-se uma teoria reflexiva; explorando textos e artigos voltados à desigualdade social e discriminação, frente aos preceitos constitucionais e instituições. Os resultados preliminares apontam que o auxílio moradia concedido aos magistrados acirra as distinções existentes entre a classe beneficiada e os demais trabalhadores, contrariando o texto constitucional vigente.

\section{O PRINCÍPIO DA IGUALDADE NO ORDENAMENTO JURÍDICO BRASILEIRO}

O princípio da igualdade constitui-se em dois significados: diferenças que formam a identidade de cada pessoa; e, desigualdades econômicas e materiais. Neste contexto, para Ferrajoli (2019) o princípio da igualdade aborda dois grandes paradigmas; (a) diferenças pessoais, a fim de distinguir as características individuais de cada pessoa; (b) diferenças materiais excessivas que influenciam para um aumento de desigualdade dentro de uma sociedade.

Segundo Ferrajoli (2019), o princípio da igualdade, também conferido como direitos fundamentais, é normativamente conferido a todos - universais - e, portanto, indisponível, já que ninguém pode privar ou ser privado deles. Deste conceito, se faz necessário uma análise a partir dos diferentes tipos de tratando em relação ao nível de classe social. Logo, o princípio da igualdade tem o papel de reduzir as desigualdades sociais.

É preciso ressaltar, contudo, a lacunas existentes que impossibilitam a efetivação desses direitos fundamentais; Desta forma, a ausência de efetivação aumenta o índice de desigualdade Estado Democrático de Direito. Diante disso, certifica-se a necessidade de medidas que possibilitem a garantia desses direitos, haja vista que, por ineficiência e pela falta desses direitos, o poder do mais forte, - ou seja, do mais privilegiado- se sobressairá frente ao mais fraco. (2019) 
O princípio da igualdade refere-se a duas questões: "igualdade em que e, igualdade entre quem" (RICCITELLI, 2007, p. 105). No sentido tradicional da palavra "igualdade", a ideia reporta-se a uma justiça, igualmente, formal; dito isso, torna-se evidente a maneira de tratamento a todos aqueles que são pertencentes a qualquer membro da sociedade. Nessa esteira, percebe-se a dificuldade em estabelecer um padrão de tratamento como forma de reconhecer as diversas categorias existentes.

Assim, reveste-se de particular importância a substituição do termo "princípio de igualdade" por parâmetros e/ou princípios de justiça, transmitindo assim a ideia de "a cada um, segundo o mérito, "a cada um, segundo a necessidade", "a cada um, segundo a condição". (RICCITELLI, 2007, p. 105). Sob essa ótica, ganha particular relevância os privilégios, também pertencentes na visão do princípio da igualdade, na medida em que configure condições que possibilitam uma característica singular, constituindo assim uma categoria em si mesmo.

Sendo assim, o princípio da igualdade é difundido em dois caminhos distintos. Neste contexto, os direitos fundamentais, conforme mencionado por Ferrajoli (2019), é o direito base do princípio da igualdade; nesta ideia, constata-se que o direito patrimonial, sendo conduzido pela dinâmica neoliberal, corrompe estruturais, teoricamente igualitárias, e impõe um mecanismo dominante camuflado com princípios fundamentais. Frente ao exposto, certifica-se que o princípio da igualdade, implica como pilar constitucional, uma vez que é capaz de reduzir os níveis de desigualdades incorporadas pelo novo modelo capitalista.

Conforme explicado acima, o princípio da igualdade se estrutura através de duas vertentes; uma com caráter fundamental para a redução das desigualdades sociais dentro de um cenário Nacional. E a outra, com caráter patrimonial, distinguindo as pessoas pelo poder aquisitivo e pela quantidade de bens em detrimento de outras. Dito isso, Cademartori acrescenta: "[...] os direitos fundamentais são fruto de condições reais ou históricas [...] ao lado de condições subjetivas, ideais ou lógicas [...] com sua ideia de igualdade de todos os homens" (1997, p.49).

Dentro dessa perspectiva, Ferrajoli (2019) apresenta uma nova proposta de igualdade jurídica, porém como igualdade de direitos fundamentais, que apresenta quatro implicações proporcionais a padrões políticos que fundamentam tantas outras formas axiológicas: (a) dignidade como forma de reconhecimento como pessoa (b), formas e subjetividades da democracia, como adventos das diferentes classes de direitos fundamentais - tais como: políticos, civis, de liberdade e sociais - universalmente conferidos a todos; (c) a paz, oriundo da 
proteção e ao respeito de todas as diferentes pessoas, como características distintas, e a redução de desigualdades econômicas; (d) a proteção dos mais fracos, tendo como protetor os direitos fundamentais, sendo assim uma alternativa, normativa, à lei dos mais fortes que se sobressairia na antinomia da lei.

Neste âmbito, os direitos fundamentais, são classificados em positivos e negativos. Os direitos fundamentais positivos ficam caracterizados por possuírem alternativas de exigência e obtenção de prestações auxiliares do Estado. Já os direitos fundamentais negativos, intimamente ligados às vertentes liberais, são caracterizados por limitarem os poderes estatais, fazendo exigências como abstenção, ou de não intervenção. (Bobbio, 1995)

Os direitos fundamentais, também reconhecidos como direitos sociais são predominantemente expandidos no século XX. Sua vinculação principal terá o princípio da igualdade como base estrutural de suas funções. Como forma de efetivação desses direitos sociais, também configurados como de segunda geração, a presença e a influência do Estado serão fundamentais para uma maior amplitude de garantias; a fim de garantir um maior equilíbrio entre as desigualdades, ou equilibrar a desigualdade sofrida pelo hipossuficiente em relação aos mais abastados economicamente.

Para Bobbio (1995), o conceito de igualdade é caracterizado como relativo e nunca como absoluto. Para o autor, dentro dessa relatividade, existem três pontos que precisam ser analisados com maior ênfase: (a) os sujeitos entre os quais se trata de repartir os bens e os ônus; (b) os bens e o ônus a serem repartidos; (c) o critério com base no qual os repartir. Sendo assim, para finalizar um projeto de repartição deve-se responder a tais perguntas: Igualdade sim, mas entre quem, em relação a que e com base em quais critérios? $\mathrm{Na}$ combinação dessas três diretrizes, tendo como obviedade, haverá uma enorme repartição passível de serem chamadas de igualitárias, apesar de serem diversas entre si.

Repara-se aqui, para Bobbio, há necessidade de existir alguns critérios a serem seguidos, junto com a distinção entre quem e em relação a que; deste modo, cabe ao poder normativo conseguir equilibrar essa desigualdade socioeconômica. Na visão de Bobbio (1995), existem procedimentos capazes de conduzir um melhor equilíbrio entre as classes, utilizando mecanismos eficientes e regras pré-estabelecidas para melhor equiparar as necessidades econômicas e sociais.

Diante desse cenário, verifica-se a necessidade de reduções das desigualdades dentro de um âmbito socioeconômico, levando o princípio da igualdade em Ferrajoli (2019) como marco 
fundamental para poder desmantelar as estruturas discriminatórias vigente no Brasil. Assim, se faz essencial uma análise crítica do auxílio-moradia para a magistratura Brasileira, haja vista a gama infinita de privilégios estabelecidos para uma classe minoritária.

\section{OS DEVERES DECORRENTES DO PRINCÍPIO DA IGUALDADE: A VEDAÇÃO À DISCRIMINAÇÃO E AS AÇÕES AFIRMATIVAS}

Ao lado do reconhecimento formal da igualdade entre todos, a CRFB autoriza de forma expressa a fixação de medidas voltadas à promoção da igualdade em relação a determinados grupos reconhecidos como vulneráveis, visto que um dos objetivos do Estado brasileiro consiste em "promover o bem de todos, sem preconceitos de origem, raça, sexo, cor, idade e quaisquer outras formas de discriminação.”, consoante previsto no artigo $3^{\circ}$, inciso IV, do texto constitucional (BRASIL, 1988).

Em outras palavras, pode-se dizer que estes são os critérios proibidos de discriminação: origem, raça, sexo, cor e idade, mostrando-se exemplificativo o rol constitucional (RIOS, 2008).

O reconhecimento constitucional das desigualdades existentes entre os indivíduos autoriza, por um lado, que certas condutas venham a ser reconhecidas como irregulares, e por outro, impõe ao estado brasileiro adoção de medidas específicas para a promoção da igualdade (RIOS, 2008).

A criminalização de condutas discriminatórias tem por objetivo impedir que sejam perpetradas agressões contra as populações vulneráveis, com a imposição de penas maiores aos responsáveis por esses atos, de forma a promover a igualdade (RIOS, 2008).

No que se refere a penalização das condutas discriminatórias, podemos apontar a previsão constitucional expressa do racismo como crime inafiançável, consoante descrito no artigo $5^{\circ}$, XLII: “a prática do racismo constitui crime inafiançável e imprescritível, sujeito à pena de reclusão, nos termos da lei;"' (BRASIL, 1988).

Os delitos relativos a preconceito de raça e cor encontram-se expressamente previstos na Lei nº 7.716, de 05 de janeiro de 1989, que dispõe, essencialmente, sobre práticas discriminatórias no âmbito das relações de trabalho, visando à promoção da Igualdade racial em âmbito público e privado (BRASIL, 1989). 
Com idêntico fundamento, observa-se a criminalização do feminicídio, em que se impõe uma pena maior ao autor de homicídio contra a mulher, tão somente em razão de sua condição sexual (BRASIL, 1940).

Ainda quanto às condutas proibidas, observa-se a criação de todo um sistema protetivo em relação a mulher, por meio da Lei Maria da Penha - Lei no . 11.340, de 07 de agosto de 2006 -, em que houve a criação não apenas de penalidades, mas também de órgãos administrativos de natureza policial para a denúncia e investigação dos crimes cometidos contra a mulher, bem como de unidades judiciárias específicas para o conhecimento de tais demandas (BRASIL, 2006).

Verifica-se, também, que criminalização das condutas discriminatórias não se dá apenas no âmbito da criação legislativa. Com efeito, o Supremo Tribunal Federal, ao julgar a Ação Direta de Inconstitucionalidade por Omissão n⿳0.26, do Distrito Federal, equiparou a homofobia e a transfobia aos crimes de racismo, inclusive admitindo a sua incidência como circunstância qualificadora em caso de homicídio, sobre o fundamento de tratar-se de motivo torpe (BRASIL, 2019) $)^{1}$

De outra parte, a vedação constitucional às condutas discriminatórias impõe ao Estado a criação de atos normativos e de políticas públicas voltadas à promoção da igualdade consoante previsto no artigo $3^{\circ}$, inciso IV, da Constituição Federal (BRASIL, 1988).

Assim, a fim de promover a igualdade ou, pelo menos, reduzir as desigualdades, temse adotado, no Brasil, desde meados da década de 1990, as chamadas ações afirmativas, as quais indicam “... o uso deliberado de critérios raciais étnicos ou sexuais com o propósito específico de beneficiar um grupo em situação de desvantagem prévia ou de exclusão, em virtude de sua respectiva condição racial étnica ou sexual” (RIOS, 2008, p. 158).

Essas medidas visam, principalmente, a conferir determinadas vantagens ou prerrogativas a certas categorias ou grupos de pessoas que se encontram em situação de desvantagem perante o homem médio na vida de relação, de forma a diminuir a as desigualdades existentes e promover a igualdade material entre tais sujeitos (RIOS, 2008).

Vale destacar que a própria CRFB, em determinadas passagens, estabelece diferenciações em favor da mulher - em relação ao período de licença maternidade e aos

\footnotetext{
${ }^{1}$ Apesar de o julgamento ter sido concluído em 13.06.2019, ainda não houve a publicação do acórdão correspondente, consoante se verifica do sítio eletrônico do Supremo Tribunal Federal na internet: http://portal.stf.jus.br/processos/detalhe.asp?incidente=4515053. Acesso em 28 set. 2020.
} 
requisitos temporais para obtenção de aposentadoria por tempo de serviço, entre outros -, com vistas a compensar, no âmbito do mercado de trabalho e da Previdência Social, alguns dos critérios de desvantagens associados ao sexo feminino (BRASIL, 1988).

Do âmbito legislativo e administrativo, tem-se, por um lado a proteção especial concedida aos portadores de necessidades especiais: Para além concessão de benefício assistencial pelo INSS àqueles que se encontram incapacitados de prover a própria subsistência, existem dispositivos legais específicos que lhes asseguram postos de trabalho na iniciativa privada e parte das vagas em concursos públicos (SARLET, 2018).

Além disso, os portadores de necessidades especiais gozam de proteção específica, em âmbito internacional estabelecida na Convenção de Nova Iorque sobre Pessoas com Incapacidade e seu Protocolo Facultativo, os quais foram incorporados ao ordenamento jurídico brasileiro com status equivalente a emenda constitucional, nos termos do artigo $5^{\circ}, \S 3^{\circ}$, da CRFB (GOMES, 2018).

Quanto aos afrodescendentes, existem políticas públicas visando a incrementar o seu acesso, por meio de cotas, nas instituições públicas de ensino superior e também no acesso ao serviço público, medidas essas que vêm sendo questionadas na sociedade a partir de uma suposta quebra na igualdade entre todos (RIOS, 2008).

No que se refere às populações indígenas e quilombolas, por sua vez, apesar de o texto constitucional de 1988 assegurar-lhes o reconhecimento da propriedade coletiva sobre as terras tradicionalmente ocupadas, bem como a sua própria cultura e instituições (BRASIL, 1988), o Estado brasileiro mostra-se recalcitrante na sua implementação, o que é fruto de uma longa tradição de desconsideração das diferenças existentes e da necessidade de assimilação de tais povos a cultura branca predominante (LACERDA, 2007).

Quanto às crianças e aos idosos, ao lado das disposições constitucionais que lhes asseguram tratamento diferenciado, existe um esforço legislativo e administrativo para sua inclusão na sociedade, seja por meio das escolas, no caso das crianças e adolescentes, seja por meio de sua efetiva participação na vida familiar, no caso dos idosos, com acesso prioritário a serviços de saúde e prioridade no julgamento em caso de ações judiciais (CARVALHO, 2018).

Além disso, os tribunais pátrios vêm reconhecendo como atos ilícitos aqueles que têm por objetivo isolar a criança e o idoso do convívio familiar, por meio da alienação parental direta ou inversa (CARVALHO, 2018). 
Em relação à mulher, tem-se buscado promover a sua igualdade, Ou pelo menos, reduzir a desigualdade por meio da adoção de políticas públicas de valorização da mulher no mercado de trabalho, seja proibindo a exigência que prova de ausência de gravidez ou de esterilização, seja por meio de campanhas que visam a igualdade de salários (CARVALHO, 2018). Em idêntico sentido, no âmbito eleitoral, foram estabelecidos percentuais mínimos reservados a candidatas a cargos eletivos em âmbito municipal, estadual, distrital e federal.

No que diz respeito às minorias sexuais, houve uma atuação intensa, desde meados dos anos 1990 à primeira metade da década de 2010, para assegurar direitos a esses sujeitos. De uma parte, estabeleceu-se, por meio de decisão judicial (posteriormente assimilada administrativamente pelo INSS), o direito dos casais homossexuais a gozar de proteção previdenciária em virtude todos os benefícios concedidos a seu cônjuge (RIOS, 2001).

De igual sorte, houve o reconhecimento do caráter familiar das relações estabelecidas entre pessoas do mesmo sexo, inclusive com reconhecimento de efeitos civis às relações homossexuais, com posterior criação do chamado casamento gay por meio de Resolução expedida pelo Conselho Nacional de Justiça (CARVALHO, 2018).

Em relação aos transexuais, admite-se atualmente a retificação do registro civil bem como a expedição de documentos oficiais com o nome social da pessoa, independentemente da realização de cirurgias de redesignação de sexo, inclusive em instituições oficiais de ensino e no âmbito do serviço público federal o que também é aplicado aos conselhos profissionais (CARVALHO, 2018).

Pode-se perceber que o ordenamento jurídico brasileiro apresenta um quadro normativo bastante amplo no que se refere à promoção da igualdade material das populações menos favorecidas (SARLET, 2018), ainda que muitas das disposições constitucionais e legais careçam de aplicação prática, especialmente nos últimos dois anos, diante da realidade política nacional.

Para além da proteção das populações vulneráveis, mostra-se inviável, ao menos em tese, o estabelecimento legal de certas prerrogativas em relação a grupos que já se encontram em situação de privilégio, o que será objeto de estudo no próximo capítulo.

\section{A QUESTÃO DO AUXÍLIO MORADIA FIXADO EM FAVOR DOS MEMBROS DA MAGISTRATURA}


O auxílio-moradia, benefício pago aos membros da magistratura nacional, foi criado

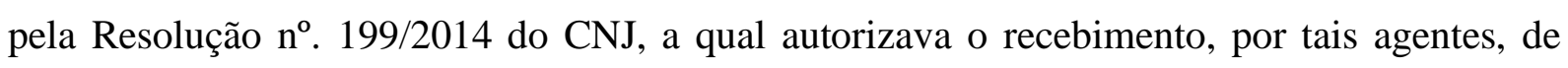
valores destinados ao ressarcimento das despesas com moradia, ainda que eles possuíssem imóvel próprio no local em que exercem suas funções jurisdicionais (BRASIL, 2018).

O referido dispositivo encontrava-se assim redigido:

Art. $1^{\circ}$ A ajuda de custo para moradia no âmbito do Poder Judiciário, prevista no art. 65, II, da Lei Complementar 35, de 14 de março de 1979, de caráter indenizatório, é devida a todos os membros da magistratura nacional. Art. $2^{\circ} \mathrm{O}$ valor da ajuda de custo para moradia não poderá exceder o fixado para os Ministros do Supremo Tribunal Federal. Parágrafo único. O valor devido a título de ajuda de custo para moradia não será inferior àquele pago aos membros do Ministério Público. Art. $3^{\circ} \mathrm{O}$ magistrado não terá direito ao pagamento da ajuda de custo para moradia quando: I - houver residência oficial colocada à sua disposição, ainda que não a utilize; II - inativo; III licenciado sem percepção de subsídio; IV - perceber, ou pessoa com quem resida, vantagem da mesma natureza de qualquer órgão da administração pública, salvo se o cônjuge ou companheiro (a) mantiver residência em outra localidade. Art. $4^{\circ}$ A ajuda de custo para moradia deverá ser requerida pelo magistrado, que deverá: I - indicar a localidade de sua residência; II - declarar não incorrer em quaisquer das vedações previstas no art. $3^{\circ}$ desta Resolução; III - comunicar à fonte pagadora da ajuda de custo para moradia o surgimento de quaisquer dessas vedações. Art. $5^{\circ}$ As despesas para o implemento da ajuda de custo para moradia correrão por conta do orçamento de cada Tribunal ou Conselho, gerando a presente Resolução efeitos financeiros a partir de 15 de setembro de 2014. Art. $6^{\circ}$ A percepção da ajuda de custo para moradia dar-se-á sem prejuízo de outras vantagens cabíveis previstas em lei ou regulamento. Art. $7^{\circ}$ Ficam revogadas as disposições regulamentares em contrário. Art. $8^{\circ}$ Esta Resolução entra em vigor na data de sua publicação. (BRASIL, 2014).

A partir do texto do ato normativo, percebe-se a criação de uma prerrogativa aos magistrados que não se estende aos trabalhadores comuns (BRASIL, 2014), o que tem ensejado muitos questionamentos acerca da sua implementação, uma vez que não há controle referente aos gastos com benefícios de natureza domiciliar. Desta forma, existem controvérsias em relação à forma de concessão do privilégio, haja vista a falta de fundamentos referente à existência ou não de moradia presente no mesmo local da comarca.

O auxílio-moradia, após sua implementação, começou a ser questionado veementemente, por grande parte da sociedade, com fundamento nos altos valores dos subsídios dos magistrados brasileiros e na ausência de normatividade para amparar uma prerrogativa com valores considerados altos. Na prática, tais valores foram postos como indenizatórios, porém o principal objetivo seria para aumentar a remuneração, já alta, dos juízes. (MORAIS, 2019)

Diante de altos salários, oriundo desde o início da carreira de um magistrado, além dos poderes e prestígio que são específicos de sua função, tornam os novos magistrados automaticamente à condição de elite econômica. (RAMOS; CASTRO, 2019). O termo elite 
pertence a um grupo específico e, na maioria das vezes, minoritário. A elite se sobressai dos demais pela quantidade de elementos e características que são altamente valorizadas no âmbito social. "A elite é simplesmente o grupo que tem o máximo que se pode ter, inclusive, de modo geral, dinheiro, poder e prestígio" (MILLS, 1981, p. 17).

Referente aos magistrados brasileiros, o termo "elite" se fundamenta em dois âmbitos. Os juízes compõem uma elite frente às demais classes sociais, devido ao prestígio, poder e remuneração elevada atribuída à prerrogativa de sua função; além disso, os magistrados compõem, majoritariamente, a bancada nos tribunais superiores, constituindo uma elite dentro do âmbito judicial, sendo assim, acabam se impondo frente aos seus próprios colegas. (MORAIS, 2019)

O simples fato de exercerem a função de juiz, sob o prisma do prestígio social em função do alto salário adquirido desde a gênese de sua carreira, indica a possibilidade de qualquer cidadão brasileiro ocupe esse status de elite. Além de formarem uma classe privilegiada, economicamente e socialmente, os juízes brasileiros ocupam a elite do serviço público brasileiro, Poder Judiciário e, inclusive, dos profissionais do ramo do direito. (RAMOS; CASTRO, 2019)

A conservação dos privilégios alcançados através da posição de magistrado, muitas vezes camuflada pelo discurso hegemônico da meritocracia, é manipulada e assegurada dentro das fronteiras das classes econômicas mais favorecidas. A repercussão é a reprodução dentro do âmbito do Poder Judiciário de visões aristocráticas e de posições ideológicas formatadas pela casta elitista composta por indivíduos privilegiados. (MORAIS, 2019).

Neste contexto, fica evidente a camada elitista formada dentro do campo judiciário, composta por indivíduos poderosos, assegurados de privilégios e prerrogativas. Como bem mencionado anteriormente, o princípio da igualdade fortaleceria o rompimento dessas desigualdades impostas pelo próprio poder constituinte, uma vez que o legislativo é pressionado pela classe aristocrata, os juízes, para satisfazer seus anseios pessoais.

O percurso inerente à magistratura brasileira é bem "popular" pelos indivíduos que participam de alguma maneira do ensino jurídico brasileiro ou que são similares a ele. Trata-se, desta forma, de jovens de classe média e alta, oriundos de camadas familiares com enorme rotatividade de capital cultural e econômico, tendo como base as melhores escolas e faculdades do país. Após o bacharelado, utilizam verbas - normalmente composta pela renda familiar para continuar se especializando por mais alguns anos na busca pela realização da tão sonhada 
e, "merecida", aprovação na magistratura. Dentro de pouco tempo os bacharéis, na maioria das vezes desempregados, passam a compor um grupo elitista tradicional do país. (RAMOS; CASTRO, 2019)

Desta forma, vale destacar, Almeida (2014, p. 87), que "as posições de elite são determinadas pela combinação cumulativa de capitais econômicos, culturais e próprios de cada campo". Dentro dessa ótica, observa se que o mérito não compõe o rol taxativo da classe elitista brasileira composta por juízes. Portanto, o discurso meritocrata, muitas vezes utilizado pela grande parte da classe elitista, não faz jus com a realidade; visto que a combinação cumulativa de capitais econômicos e culturais beneficia uma classe minoritária na busca pela tão “merecida" vaga no setor público.

Neste cenário, o compartilhamento de um costume elitista desigual e privilegiado, que promove, na grande maioria, preferências antidemocráticas e vontades de promoção de privilégios, parece conflitante com uma efetivação e implementação de igualdade em condições para o cumprimento de prerrogativas democráticas.

Nestes termos, o auxílio-moradia, à luz das considerações de Ricardo Alexandre, também caracterizado como verba indenizatória, representa a cobertura de despesas referente a alugueis, como forma de moradia para os magistrados, - muito que magistrado vá morar em algum imóvel alugado -, ou outro meio que possa cobrir os desejos dos juízes em relação a sua hospedagem. (ALEXANDRE; DEUS, 2017)

Portanto, o valor agregado a sua remuneração independe se o magistrado possuí ou não residência fixa. Dito isso, constata-se que a maioria dos magistrados, do município de São Paulo, gozam do auxílio-moradia mesmo tendo imóveis em seu nome. (TAKAHASHI; BRAGON; MATTOSO; MARIANI, 2018).

De acordo com Hely Lopes Meirelles (2012), valores indenizatórios, via de regra, deverão estar previstas em lei, não havendo possibilidade de serem revertidas para remuneração indireta, observando que prevalece, a razoabilidade. Nesta esteira, pergunta-se, mais uma vez, a natureza jurídica do auxílio-moradia para magistrados e seus possíveis resultados normativos.

Ainda nessa esteira, cabe salientar o impacto orçamentário que o auxílio-moradia ocasionou aos cofres públicos. No primeiro ano de auxílio, após a concessão das liminares, o benefício acabou custando ao cidadão contributário cerca de $\mathrm{R} \$ 863$ milhões de reais. Como forma de exemplificar, o Tribunal de Justiça do Paraná - TJPR, uma única magistrada recebia, antes da liminar de 2014, um pouco mais de $\mathrm{R} \$ 1.000,00$ designado a indenização. Logo após 
a liminar, a magistrada começou a receber seis vezes mais, alavancando um gasto de $447 \%$ (VOITCH, 2014).

Diante de exposto, fica evidente que a elite judicial brasileira prolifera a sua posição numa retórica meritocrata individualista em razão de sua gama infinita de privilégios. Nessa medida, a classe elitista - aristocrática - constrói uma ideologia que, rigorosamente, humilha aos que não conseguiram construir, dentro de uma retórica "meritocrata", uma carreira prestigiosa. Dentro desse contexto, fica claro a existência de uma estrutura desigual e discriminatória dentro do Poder Judiciário; a ponto de beneficiar algumas classes em detrimento de outras.

\section{CONCLUSÕES}

Não há dúvidas de que os magistrados brasileiros gozam de privilégios que não se confundem com o cidadão comum brasileiro. Ainda que tais agentes tenham prerrogativas expressamente previstas na CRFB (inamovibilidade, vitaliciedade e irredutibilidade de vencimentos) como forma de garantir sua independência perante os Poderes Legislativo e Executivo, não há fundamento jurídico capaz de justificar a percepção do auxíio-moradia.

O Poder Judiciário Brasileiro justifica seu discurso meritocrata contrariando sua órbita estruturada em privilégios e "regalias" em função de sua posição socioeconômica, a retórica se conflita com as práticas vigentes na sociedade, onde o órgão deveria garantir as constituições rígidas e os princípios constitucionais, como a liberdade e a igualdade.

Dentro desse cenário, a elite aristocrática - composta pelos magistrados brasileiros -, reproduzem uma estrutura desigual e discriminatória, visto que utilizam de sua posição socioeconômica para impor suas vontades frente aos padrões normativos.

A magistratura brasileira admite, dentro de um parâmetro semelhante, a sua natureza economicamente privilegiada de que usufruem, afetando diretamente a natureza pluralista e democrática do Estado brasileiro; visto que são direitos a serem promovidos em sua Carta Magna.

Fora isso, o valor exorbitante de seus salários, seguido de verbas indenizatórias, possibilita que os magistrados entrem ou permaneça numa casta economicamente privilegiada, indicando assim uma reprodução de uma estrutura aristocrática - admitindo, deste modo, uma classe extremamente favorecida em relação a outras. 
O efeito, perverso, desse afastamento inevitável entre juízes e a grande população brasileira, distancia o convívio harmônico e satisfatório da grande parte dos cidadãos. Ao adquirirem essa gama infinita de privilégios e "regalias" a classe dos magistrados se torna infinitamente superior à verdadeira classe brasileira. De tal forma, os benefícios - muitas vezes impostos pelo Poder Judiciário - discriminam descaradamente a essência do povo brasileira, visto que o auxílio-moradia é quatro vezes mais alto do que o salário mínimo vigente do país.

Outra consequência desse perverso afastamento se dá no próprio sentido funcional da jurisdição, uma vez que o magistrado deveria ser meramente um servidor a serviço do público, porém tal função acaba sendo vista como junção de privilégios e salários exorbitantes frente à sociedade brasileira, muitas vezes pobre.

A magistratura brasileira, composta por uma classe extremamente elitista, possuí requisitos vantajosos comparados ao cidadão comum brasileiro. Dentro dessa perspectiva, o cidadão popular brasileiro se vê discriminado, haja vista a desvalorização do seu salário mínimo; hoje, em normas vigentes, o cidadão brasileiro recebe quatro vezes menos que o benefício de auxílio-moradia de um magistrado. A capacidade econômica de um brasileiro não é comparada a um aristocrata do Poder Judiciário, devido à falta de garantias constitucionais a uns e a multiplicidade de "regalias" a outros.

A violação aos princípios constitucionais pelo Poder Judiciário, promove a desigualdade social e a discriminação das diferenças dentro de um mesmo ambiente de convivência. Aquele que foi destinado a ser o guardião da carta constitucional brasileira viola preceitos, constitucionalmente fundamentais, para satisfazer interesses próprios e se apoderar frente a gama infinita de prerrogativas devido a sua função.

Referente ao exposto chega-se a conclusão que o auxílio-moradia viola alguns princípios basilares do Estado Democrático de Direito. Desta forma, o auxílio-moradia se torna benefício injustificado, haja vista seu caráter indispensável à função de magistrado. Conforme previsto no CNJ, tal benefício é caracterizado como indenização, fortalecendo mais uma vez a violação aos princípios constitucionais.

Esse cenário se encaminha para maiores desigualdades sociais e discriminações diversas devido à falta de garantias fundamentais frente à lei dos mais fortes. O cidadão brasileiro busca, frente a tantas desigualdades socioeconômicas vigentes, uma saída pra a perversa crise existencial dentro dos três poderes. Hoje a situação se agrava a cada dia, devido à falta de 
implementação de políticas públicas norteadoras para a remoção ou pelo menos redução de desigualdades e discriminações.

\section{REFERÊNCIAS}

ALEXANDRE, Ricardo; DEUS, João de. Direito Administrativo Esquematizado. São Paulo: Método. 2017. Disponível em: https://www.docsity.com/pt/direito-administrativo2017ricardo-alexandre-e-joao-de-deus-pdf/5159460/. Acesso em: 20 set. 2020.

ALMEIDA, Frederico de. As elites da Justiça: Instituições, profissões e poder na política da justiça brasileira. Revista de Sociologia Política, v. 22, n. 52, p. 77-95, 2014. Disponível em: https://www.scielo.br/pdf/rdgv/v15n2/2317-6172-rdgv-15-02-e1918.pdf. Acesso em: 22 set. 2020.

BOBBIO, Norberto. Direita e Esquerda: Razões e significados de uma distinção política. São Paulo: Universidade Estatual Paulista, 1995. Disponível em: https://bok.lat/book/3358501/7509bc. Acesso em: 10 set. 2020.

BRASIL. Conselho Nacional de Justiça. Resolução no. 199, de 2014. Disponível em: https://atos.cnj.jus.br/atos/detalhar/atosnormativos?documento=2076\#: :text=RESOLVE\%3 A,os\%20membros\%20da\%20magistratura\%20nacional. Acesso em: 28 set. 2020.

Constituição (1988). Constituição da República Federativa do Brasil. Disponível em: http://www.planalto.gov.br/ccivil 03/constituicao/constituicaocompilado.htm. Acesso em: 05 set. 2020.

Decreto- Lei no . 2.848, de 07 de dezembro de 1940. Código Penal. Disponível em: http://www.planalto.gov.br/ccivil 03/decreto-lei/del2848compilado.htm. Acesso em: 28 set. 2020.

Lei $\mathbf{n}^{0}$. 7.716. de 05 de janeiro de 1989. Define os crimes resultantes de preconceito de raça ou de cor. Disponível em: http://www.planalto.gov.br/ccivil 03/leis/L7716compilado.htm. Acesso em: 28 set. 2020.

Lei $\mathbf{n}^{0}$. 11.340, de 07 de agosto de 2006. Cria mecanismos para coibir a violência doméstica e familiar contra a mulher, nos termos do $\S 8$ o do art. 226 da Constituição Federal, da Convenção sobre a Eliminação de Todas as Formas de Discriminação contra as Mulheres e da Convenção Interamericana para Prevenir, Punir e Erradicar a Violência contra a Mulher; dispõe sobre a criação dos Juizados de Violência Doméstica e Familiar contra a Mulher; altera o Código de Processo Penal, o Código Penal e a Lei de Execução Penal; e dá outras providências. Disponível em: http://www.planalto.gov.br/ccivil_03/_ato20042006/2006/lei/111340.htm. Acesso em: 12 set. 2020.

Supremo Tribunal Federal. STF enquadra homofobia e transfobia como crimes de racismo ao reconhecer omissão legislativa. Brasília: 13 jul. 2019. Disponível em: 
http://www.stf.jus.br/portal/cms/verNoticiaDetalhe.asp?idConteudo=414010. Acesso em: 28 set. 2020.

Teses

disponíveis

em: http://www.stf.jus.br/arquivo/cms/noticiaNoticiaStf/anexo/tesesADO26.pdf. Acesso em: 28 set. 2020.

CADEMARTORI, Sérgio. Estado de direito e legitimidade: uma abordagem garantista. Millennium; $2^{a}$ Edição. 1997.

CARVALHO, Dimas Messias. Direito das Famílias. 6 ed. São Paulo: Saraiva Educação, 2018.

FERRAJOLI, Luigi. Manifiesto por la Igualdad, (Trad. Perfecto Andrés Ibañez). Editorial Trotta, S.A., 2019. - Madrid.

GOMES, Jesus Tupã Silveira. Controle de Convencionalidade no Poder Judiciário: Da hierarquia normativa ao Diálogo com a Corte Interamericana de Direitos Humanos. Curitiba: Juruá, 2018.

LACERDA, Rosane Freire. Diferença não é incapacidade: gênese e trajetória histórica da concepção da incapacidade indígena e sua insustentabilidade nos marcos do protagonismo dos povos indígenas e do texto constitucional de 1988. 2007. 2 v. Dissertação (Mestrado em Direito)-Universidade de Brasília, Brasília, 2007. Tomo II. Disponível em: <http://repositorio.unb.br/handle/10482/3545>. Acesso em 28 Ago 2016.

MEIRELLES, Hely Lopes. Direito Administrativo Brasileiro. São Paulo. Malheiros, 2012.

MILLS, Charles Wright. A elite do poder. Tradução de Otávio GuilhermeVelho. 4. ed. Rio de Janeiro: Zahar, 1981. Disponível em: https://b-ok.lat/book/1206568/43f228. Acesso em: 10 set. 2020.

MORAIS, Vitória Larissa Dantas de. Prerrogativa ou Privilégio: Uma análise do auxílio moradia para juízes à luz dos princípios constitucionais da moralidade e da legalidade. 2019. Disponível em: https://repositorio.ufersa.edu.br/handle/prefix/3470. Acesso em: 15 set. 2020.

RAMOS, Marcelo Maciel; CASTRO, Felipe Araújo. Aristocracia judicial brasileira: privilégios, habitus e cumplicidade estrutural. Revista Direito GV, v. 15, n. 2, 2019. Disponível em:

https://www.scielo.br/scielo.php?pid=S1808-24322019000200205\&script=sci_arttext

Acesso em 15 set. 2020.

RIOS, Roger Raupp. A Homossexualidade no Direito. Porto Alegre: Livraria do Advogado, 2001.

Direito da Antidiscriminação: Discriminação Direta, Indireta e Ação Afirmativa.

Porto Alegre: Livraria do Advogado, 2008. 
RICCITELLI, Antonio. Direito Constitucional: teoria do Estado e da Constituição. 4. ed. Baruei: Manole, 2007.

TAKAHASHI, Fábio; BRAGON, Ranier; MATTOSO, Camila; MARIANI, Daniel. Metade dos juízes que ganham auxílio moradia em SP tem imóvel. Folha de S. Paulo. 4 fev 2018. Disponível em: https://www1.folha.uol.com.br/poder/2018/02/metade-dos-juizes-queganham-auxilio-moradia-em-sp-tem-imovel.shtml. Acesso em: 25 set. 2020.

VOITCH, Guilherme. Auxílio-moradia aumenta despesas do TJPR em 447\%. Jota. 24 nov 2014. Disponível em:

http://www.jota.info/paywall?redirect to=//www.jota.info/justica/auxilio-moradia-aumentadespesas-tj-pr-em-447-24112014. Acesso em: 27set. 2020. 